\title{
Observations regarding historical accounts of pneumococcal diseases due to serotypes I and 3
}

\author{
${ }^{1} \mathrm{DJ}$ Inverarity, ${ }^{2} \mathrm{MA}$ Diggle \\ ${ }^{1}$ Consultant Microbiologist, Monklands Hospital, Airdrie, Lanarkshire; ${ }^{2}$ Clinical Microbiologist, Department of Microbiology, Nottingham \\ University Hospitals Trust, Nottingham, UK
}

\begin{abstract}
Surveillance of the serotypes causing invasive pneumococcal diseases in the UK has indicated increasing incidence of serotype I- and serotype 3-related disease in recent years. The introduction of a pneumococcal conjugate vaccine to the paediatric vaccination schedule in 2006 , which did not cover these serotypes, has been regarded as a contributing factor. Serotypes I and 3 were perhaps the most extensively studied pneumococcal serotypes in the early twentieth century when pneumococcal serotyping began. Such historical observations are pertinent to our understanding of contemporary disease manifestations for these serotypes as many parallels can be seen between their behaviour in the early twentieth century and the early twenty-first century. There are many relevant lessons to be learned from these pre-antibiotic era descriptions and the observations of our predecessors.
\end{abstract}

KEYWORDS Epidemiology, pneumococcus, serotype, Streptococcus pneumoniae

Correspondence to DJ Inverarity, Department of Microbiology, Monklands Hospital, Monkscourt Avenue, Airdrie ML6 0JS, UK

tel. $+44(0) 1236712118$ e-mail donald.inverarity@ lanarkshire.scot.nhs.uk

DECLARATION OF INTERESTS No conflict of interests declared.

\section{INTRODUCTION}

Infections due to Streptococcus pneumoniae (the pneumococcus) remain a substantial source of morbidity and mortality in both developing and developed countries, despite a century of study and the development of antibiotics and vaccination. The World Health Organization (WHO) estimates that in developing countries 814,000 children under the age of five die annually from invasive pneumococcal diseases,' with an estimated I.6 million deaths affecting all ages globally. ${ }^{2}$

Pneumococcal serotypes I and 3 were among the first to be discovered and characterised. Unlike virtually every other pneumococcal serotype, serotypes I and 3 have not undergone reclassification or subcategorisation to any great degree. This enables earlier descriptions of disease manifestations due to these serotypes to be compared with more contemporary work with some confidence that the descriptions relate to the same phenotypic type of pneumococcus.

The epidemiology of invasive pneumococcal disease (IPD), particularly with regard to serotypes I and 3 , has recently been under scrutiny. The introduction of the seven-valent pneumococcal conjugate vaccine (Prevenar $^{\circledR}$, Wyeth) into the British paediatric vaccination schedule in September 2006 raised concerns that there might be a resurgence in pneumococcal diseases due to serotypes $I$ and 3 as they are not preventable using this vaccine. Published descriptions of serotype I- and 3-associated IPD during the twentieth century indicate that their incidence has fluctuated even without vaccine selection pressure. The incidence of IPD due to serotype I was increasing in Britain before the introduction of
Prevenar ${ }^{\circledR 3-5}$ and the increasing incidence of paediatric empyema cases due to serotype I has been of particular concern. ${ }^{6,7}$ In 2010 Prevenar $^{\circledR}$ was replaced by Prevenar $13^{\circledR}$ (Wyeth), which is an updated conjugate vaccine providing additional protection against serotypes I, 3, 5, 6A, 7F and 19A. Its effects on the incidence of serotype $\mathrm{I}$ - and serotype 3-associated IPD remain to be seen. The recognised increase in IPD following influenza pandemics and epidemics ${ }^{8-11}$ is also of current interest, given the recent declaration by the $\mathrm{WHO}$ that the influenza $\mathrm{A}$ pandemic (HINI) 2009 is considered over. Much of the post-1918 pandemic IPD morbidity and mortality was due to serotype $1 .^{12}$

Early accounts of serotype I disease often contradict contemporary descriptions of its behaviour by demonstrating carrier states and environmental reservoirs of infection. Historical descriptions of serotype I- and 3-associated IPD demonstrate marked differences in study design, geographical location, methodology of culture (by blood agar or mouse peritoneal inoculation) and reporting of results. But despite these variations, the descriptions of disease manifestations and serotype prevalences at the start of the twentieth century appear to differ from those at its end. Often sufficient detail has been documented in the pre-antibiotic era to provide useful insights when faced with similar scenarios 100 years on.

\section{DEFINITIONS AND SURVEILLANCE}

The classification of pneumococci has developed over the past century. In 1909 Neufeld and Händel identified a pneumococcus from cases of lobar pneumonia and raised antibodies in horses and donkeys, allowing a serological identification for the first time. ${ }^{13}$ In 1913 , the 


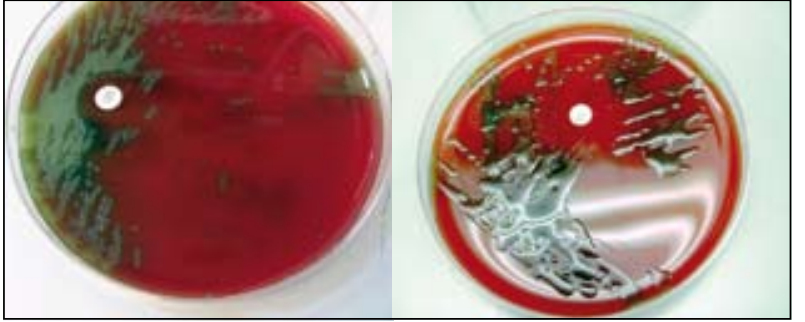

FIGURE I Comparison of the phenotypic appearances of serotype I and serotype 3 pneumococci. On the left, discrete, optochin-sensitive, alpha-haemolytic colonies of serotype I pneumococci are visible on blood agar. On the right, serotype 3 pneumococci, although still optochin-sensitive and alphahaemolytic, demonstrate indistinct mucoid colonies.

(With thanks to Jim Donnelly, Biomedical Scientist, Monklands Hospital Department of Microbiology.)

Rockefeller Institute in New York and the South African Institute for Medical Research in Johannesburg published serologically based typing schemes for pneumococci, ${ }^{14,15}$ although subsequently the South African scheme fell into disuse. The Rockefeller Institute Type II grouping was found to be heterogeneous ${ }^{16}$ and probably consisted of several different contemporary serotypes and so cannot be compared with serotype 2 in modern descriptions. It is likely though that the Rockefeller Institute Type I pneumococcus is equivalent to the modern serotype I pneumococcus.

In 1903, Schottmüller described Streptococcus mucosus, ${ }^{17}$ but work in 1905 suggested S. mucosus should be reclassified as a pneumococcus. ${ }^{18,19}$ S. mucosus (renamed Pneumococcus mucosus) was described in 1917 as 'larger, rounder, and less lanceolate than other types of pneumococcus' and possessing 'a large distinct capsule'. ${ }^{20}$ It grew on blood agar with colonies which were 'moist, mucoid, and confluent' and became known as the Type III pneumococcus. ${ }^{20}$ This phenotypic description matches that which would be seen for contemporary serotype 3 isolates (Figure I). There is potential for misclassification when only the phenotypic appearances are used to classify serotype 3 as mucoid colonies can be observed in some other pneumococcal serotypes, albeit uncommonly. ${ }^{21}$ It was not until 1934 that Type III could be distinguished serologically from phenotypically similar Type VIII. ${ }^{22}$ So only after 1934 can it be concluded that the Type III pneumococcus is equivalent to the contemporary serotype 3 pneumococcus.

In the absence of antibiotics and with growing success in the treatment of lobar pneumonia using type-specific horse or rabbit sera, ${ }^{23}$ serotyping of disease-related isolates of pneumococci became important in order to use the correct antisera as therapy. Lobar pneumonia was a reportable illness and in the 1920s the prevalence of, and mortality associated with, the different serotypes of pneumococci responsible for lobar pneumonia and other invasive disease manifestations began to be documented in Britain. This continued throughout the 1930s.

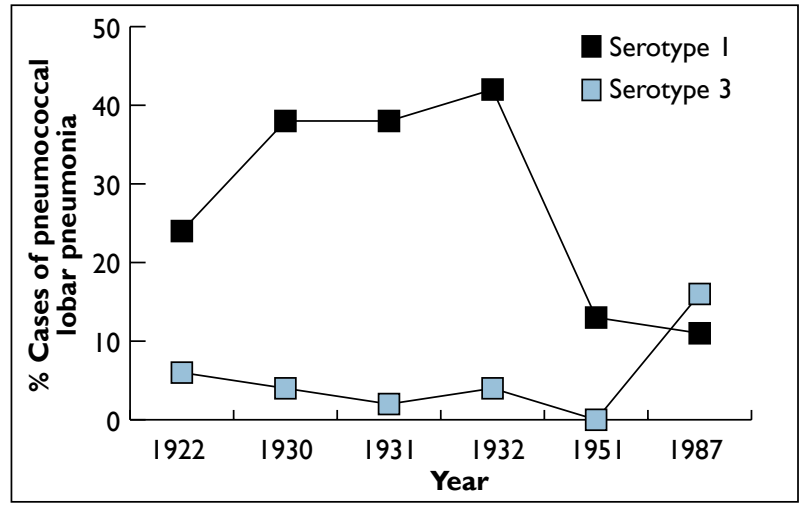

FIGURE 2 Proportions of cases of hospitalised pneumococcal lobar pneumonia due to serotypes I and 3 documented in Glasgow during the twentieth century. ${ }^{24-28} \mathrm{~A}$ marked decline in serotype I disease is evident over the period, even recognising that many of the original papers in the pre-antibiotic era included both patients who received anti-pneumococcal serum and those who did not.

The discovery of sulphonamide and penicillin antibiotics (which no longer required a knowledge of serotype to determine appropriate treatment) resulted in a decline in interest in pneumococcal serotyping from the 1940s until the 1980s when it again became important to determine the composition of local pneumococcal populations as polysaccharide vaccines were being introduced. By this time (likely due to the success of its pharmacological treatment), lobar pneumonia was no longer a notifiable condition. Consequently serological surveillance switched to documenting instances of pneumococcal bacteraemia and meningitis to record IPD cases. This makes contemporary serological surveillance records difficult to compare with those from earlier in the twentieth century.

\section{CHANGES IN DISEASE BURDEN}

Figures 2 and 3 demonstrate the burden of disease caused by serotype I (Type I) and serotype 3 (Type III) pneumococci in Glasgow and Edinburgh from the 1920s until the 1980s. Only data from original papers which pertained to cases of pneumococcal lobar pneumonia and the percentage frequency with which this was caused by serotype I or 3 are displayed. Table I lists the results, from other British studies, of the serotypes responsible for pneumococcal lobar pneumonia or all types of pneumonia.

The burden of pneumococcal disease in Scotland was first documented by Logan in 1918-19.10 Three of 34 (8.9\%) cases of pneumococcal bronchopneumonia were due to Type I pneumococci and two of 34 (5.9\%) due to Type III pneumococci. It is likely that these small numbers underestimate the disease burden at the time, particularly as they occurred during the 1918 influenza pandemic (when there was increased incidence of IPD); they are therefore not included in Figures 2 or 3.

Cowan et al. ${ }^{27}$ gathered data relating to hospitalised cases of lobar pneumonia admitted to the Glasgow 


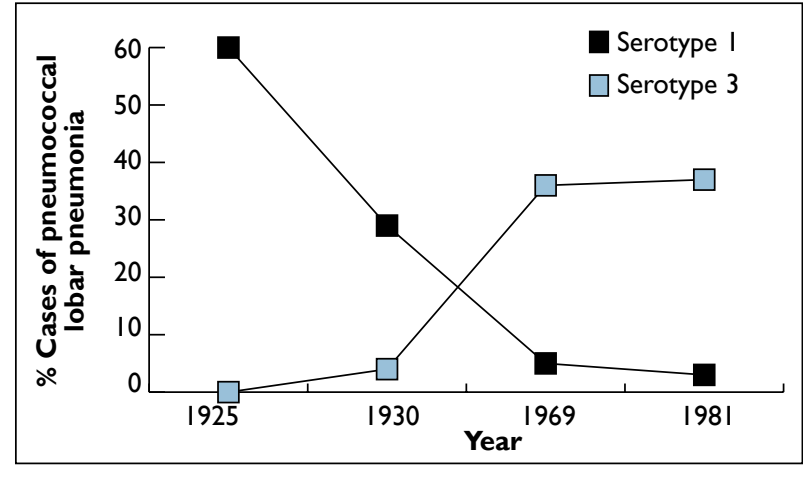

FIGURE 3 Proportions of cases of hospitalised pneumococcal lobar pneumonia in Edinburgh due to serotypes I and 3 in the twentieth century show the same dramatic fall in the proportion of cases of serotype I-associated disease as in Glasgow. ${ }^{29-32}$

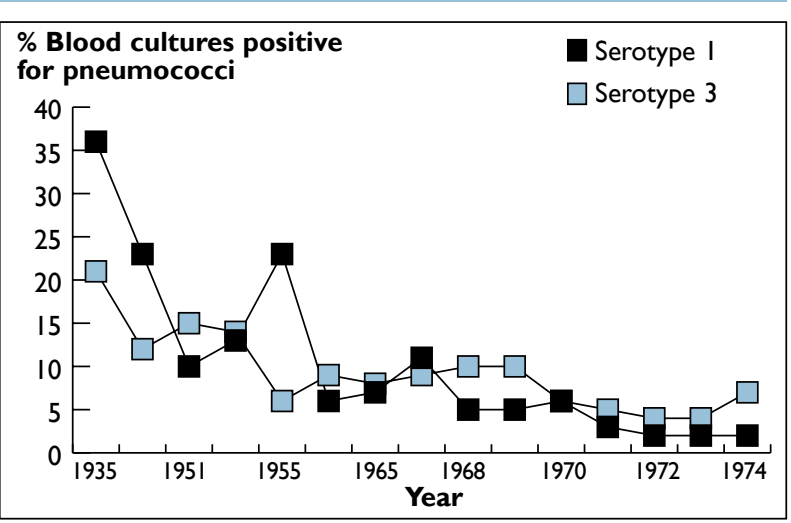

FIGURE 4 Proportions of blood cultures growing pneumococci at Boston City Hospital due to serotype I and serotype 3 (1935-1974), ${ }^{41}$ also showing a dramatic fall in cases of serotype I associated disease during the 1950s and 1960s similar to that seen in Scotland but without the noteworthy associated rise in the proportion of cases due to serotype 3 during the early 1970s.

Royal Infirmary, Victoria Infirmary, Western Infirmary and the Royal Hospital for Sick Children in Glasgow from 1930-32 and helpfully displayed the incidence of Type I, II, III and IV pneumococci by age in cases of pneumococcal lobar pneumonia. In this pre-antibiotic era study, serotype I- and serotype 3-related pneumococcal pneumonia was predominantly a disease of children and young adults. It was much less common in the over-50s, unlike the age distribution currently in Scotland where infants and the elderly are the predominant age groups affected. ${ }^{40}$

It is difficult to make meaningful comparisons of the disease burden from what would now be considered IPD. There is a lack of documentation about the methodology of blood culture technique (although it is fair to assume that it was not standardised between locations and over time). Intraperitoneal mouse inoculation was often preferred for culturing clinical specimens in the past rather than direct inoculation of specimens onto agarbased media as is routine today. ${ }^{24}$ Finland and Barnes demonstrated an obvious decline in cases of serotype I and serotype 3 blood stream infection in Boston, USA, between 1935 and 1974 (Figure 4), which does
TABLE I Studies documenting the proportions of serotype $\mathrm{I}$ - and serotype 3-associated disease in the twentieth century from locations in the UK other than Glasgow and Edinburgh

\begin{tabular}{|c|c|c|c|c|c|}
\hline ฝे & בְ & 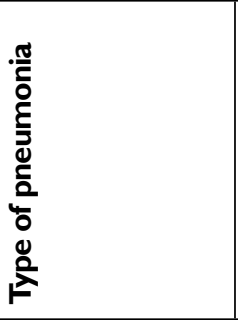 & 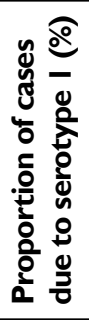 & 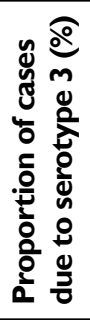 & 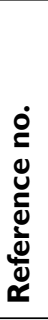 \\
\hline $\begin{array}{l}1919 \\
-21\end{array}$ & Liverpool & $\begin{array}{l}\text { Hospitalised } \\
\text { cases of pneumo- } \\
\text { coccal lobar } \\
\text { and broncho- } \\
\text { pneumonia (adult } \\
\text { and paediatric) }\end{array}$ & 37.7 & 1.5 & 12 \\
\hline 1921 & London & $\begin{array}{l}\text { Hospitalised } \\
\text { adult lobar } \\
\text { pneumonia }\end{array}$ & 50 & 0 & 33 \\
\hline 1922 & London & $\begin{array}{l}\text { Hospitalised } \\
\text { lobar pneumonia } \\
\text { (adult and } \\
\text { paediatric) }\end{array}$ & 35.7 & 2.9 & 34 \\
\hline $\begin{array}{l}1920 \\
-22\end{array}$ & $\begin{array}{l}\text { West } \\
\text { Midlands }\end{array}$ & $\begin{array}{l}\text { Hospitalised } \\
\text { lobar pneumonia }\end{array}$ & 30.6 & 6.6 & 35 \\
\hline $\begin{array}{l}1922 \\
-24\end{array}$ & $\begin{array}{l}\text { West } \\
\text { Midlands }\end{array}$ & $\begin{array}{l}\text { Hospitalised } \\
\text { lobar pneumonia }\end{array}$ & 42.6 & 3.2 & 35 \\
\hline $\begin{array}{l}1924 \\
-27\end{array}$ & $\begin{array}{l}\text { West } \\
\text { Midlands }\end{array}$ & $\begin{array}{l}\text { Hospitalised } \\
\text { lobar pneumonia }\end{array}$ & 34.3 & 4.4 & 35 \\
\hline $\begin{array}{l}1925 \\
-27\end{array}$ & Manchester & $\begin{array}{l}\text { Hospitalised } \\
\text { lobar pneumonia } \\
\text { (adult and } \\
\text { paediatric) }\end{array}$ & 43.1 & 0 & 36 \\
\hline $\begin{array}{l}1969 \\
-77\end{array}$ & Oxford & $\begin{array}{l}\text { All types } \\
\text { (adults treated } \\
\text { in hospital) }\end{array}$ & 20.8 & 19.4 & 37 \\
\hline $\begin{array}{l}1980 \\
-81\end{array}$ & Nottingham & $\begin{array}{l}\text { All hospitalised } \\
\text { adults with } \\
\text { community- } \\
\text { acquired } \\
\text { pneumonia }\end{array}$ & 17.5 & 23 & 38 \\
\hline $\begin{array}{l}1980 \\
-81\end{array}$ & London & $\begin{array}{l}\text { All hospitalised } \\
\text { respiratory tract } \\
\text { infections (adult } \\
\text { and paediatric) }\end{array}$ & 15.6 & 11 & 39 \\
\hline
\end{tabular}

correspond with the use of antibiotics. Although no mention is made of any changes in blood culture methodology during that period, it would be counterintuitive to assume that any improvements in blood culture methodology introduced would produce a reduction in the detection rates of the pneumococcus. ${ }^{41}$

Smeall from the Royal Infirmary of Edinburgh documented 24 cases of pneumococcal meningitis between 1929 and $1931 . .^{42}$ Four of these (16.7\%) were due to Type I and seven $(29.1 \%)$ due to Type III. Smeall also made the observation that six of the seven cases $(86 \%)$ of the Type 
III-related meningitis cases were related to otitis media and mastoiditis. ${ }^{42}$

A further condition where some comparison can be made is in the occurrence of pneumococcal empyema in both adults and children. This was well documented by Glynn and Digby. ${ }^{12}$ Much of their data came from the Royal Children's Hospital in Liverpool. Data from Scotland regarding empyema were again recorded by Smeall in Edinburgh from 1929-31. Of 21 cases, 14 (66.7\%) were due to Type I and only one $(4.7 \%)$ was due to Type III. ${ }^{42}$ It would appear that during the 1920s, serotype I-related pneumococcal empyema was a common manifestation of serotype I disease, accounting for up to $53 \%$ of serotype I-related disease and $77 \%$ of all cases of pneumococcal empyema in one British series, ${ }^{43}$ while serotype 3 -related pneumococcal empyema was rare (6\%). ${ }^{43}$ The current increase in serotype I-related paediatric empyema in the $\mathrm{UK}^{6,7}$ may then not necessarily be a new phenomenon but may be the initial signs of the serotype I pneumococcal population reverting back to a previous higher incidence.

\section{MORTALITY}

Many factors have influenced the mortality from IPD in Britain, including concurrent influenza infection, the use of serum therapy, antibiotics and subsequently national vaccination programmes for the elderly and infants. So comparisons of the mortality associated with different serotypes cannot be accurately made over a long period of time. However, when the mortality associated with serotype I and serotype 3 is compared at specific time points in studies of patient populations of a similar age range and geographical setting, it is apparent that a difference may exist between the serotypes.

In 1917, when no effective treatment other than symptomatic relief was possible, Avery in New York documented a mortality of $25 \%$ for Type l-associated lobar pneumonia and $45 \%$ for Type III. ${ }^{20}$ In untreated patients in Glasgow the mortality rates were lower at 10\% for Type I and $29 \%$ for Type III, albeit in a study performed 13 years later. ${ }^{27}$ A further study at the Rockefeller Institute in 1917-1921 assessed mortality from all hospitalised pneumonia cases; the mortality associated with Type I was 15\% and Type III was $60 \%{ }^{44} \mathrm{~A}$ drop in mortality from Type I disease could be accounted for by the inclusion of patients who had received serum therapy against Type I during this period. In 1921, in a study of 195 cases of Type I pneumonia treated with serum therapy, Cole found that the mortality rate at the Rockefeller Institute had fallen to $9.2 \%$. $^{23}$

The greater mortality from Type III in the Thomas study ${ }^{44}$ may be due to the inclusion of cases which occurred during the 1918-19 influenza pandemic. It is calculated that in England and Wales in the 1919 post-influenza pandemic, 7,985 people contracted Type I pneumococcal pneumonia and about 4,000 died from it. ${ }^{12} \mathrm{~A}$ marked rise in the detection of pneumococcal blood stream infections during the 1918 Louisiana influenza epidemic was shown by McClelland when, pre-influenza, positive blood cultures were detected in $19.1 \%$ of cases of pneumococcal lobar pneumonia (all types) with an associated mortality of $25 \%$, rising to $46 \%$ with an associated mortality of $88 \%$ during the influenza pandemic. ${ }^{45}$ An effect of influenza on mortality from pneumococcal disease was also documented by Alston and Stewart at the Royal Infirmary of Edinburgh in 1929-30 during an influenza epidemic when mortality in hospitalised cases of lobar pneumonia associated with the Type I pneumococcus was $23 \%$ and that due to Type III 71\%. ${ }^{29}$ In 1922, Lyon in Boston, USA, observed that Type III pneumococcal bloodstream infection in children was invariably fatal. ${ }^{46}$

Even after the extensive use of penicillin and withdrawal of serum therapy as the mainstay of therapy, there is a difference in mortality associated with serotype I and serotype 3 pneumococci. A small series of cases of hospitalised, community-acquired pneumococcal pneumonia from Nottingham in 1981 found that nine of 24 (37\%) of patients with serotype 3 infection died, compared with three of 18 (17\%) with serotype I infection. It was observed that serotype 3 accounted for about $25 \%$ of all the pneumococcal pneumonia cases but for more than $50 \%$ of fatalities from the disease. ${ }^{38}$ The association of serotype 3 IPD and an increased risk of a fatal outcome compared with serotype I has been more recently documented in other European countries. ${ }^{47-50}$ Overall these studies concur with Stillman's observation in 1916 that 'although this organism [Type III] is responsible for but a small percentage of the cases of lobar pneumonia, it produces an unusually severe type of the disease'. ${ }^{51}$

\section{CARRIER STATES OF SEROTYPES I AND 3}

Observations about a carrier state for Type I and Type III pneumococci are often different in the pre-antibiotic era compared with modern times. Dochez and Avery in 1915 noted carriage of Type I pneumococci in three of 66 (4.5\%) pneumococcal carriers who were 'normal individuals', but they were unable to assess Type III carriage rates due to a lack of Type III antisera. ${ }^{52}$ In 1917 Stillman wrote that 'although pneumococcus is present in the mouths of about fifty percent of normal individuals, it is extremely rare to find pneumococcus of Type $I$ in the normal mouth except in individuals who have been in intimate association with patients suffering from lobar pneumonia'. ${ }^{53}$ This was a conclusion based on his earlier observation that only four of $172(2.3 \%)$ pneumococcal oropharyngeal carriers carried Type I and 44 of the 172 (26\%) carried Type III. Moreover, carriage of Type III persisted in some cases for more than three months, while carriage of Type I lasted for up to 90 days after recovery from pneumoccal pneumonia. ${ }^{52}$ Strom in 1932 also recorded a long period of Type I carriage -73 days 
after recovery from pneumonia. ${ }^{54}$ So accounts from the pre-antibiotic era document that a healthy carrier state of Type I can and did occur in individuals in close contact with cases and for prolonged periods in those who had recovered from Type l-associated lobar pneumonia.

Interestingly, modern studies of the serotypes detected from asymptomatic pneumococcal carriers often suggest that it is uncommon to find serotype I being carried by individuals. Serotype 3 carriage is more common in such studies..$^{55}$ In keeping with this, Meyer in 1920 demonstrated higher Type III carriage rates than for Type I, which was not detected. ${ }^{56}$

In 1917, Stillman cultured sputa from 107 healthy household contacts of 28 patients admitted with Type I lobar pneumonia and found that 15\% were Type I carriers. ${ }^{53}$ For these healthy contacts, the average period of carriage was 25 days for Type I, potentially providing a reservoir for further infection. In the same year, Avery and colleagues noted a Type I carriage rate of $13 \%$ in the contacts of cases of lobar pneumonia and only $0.33 \%$ in controls who had no contact with cases of lobar pneumonia. ${ }^{20}$ Type I carriers harboured it for three to four weeks. ${ }^{20}$ Similar differences between contacts and controls with regard to Type I carriage were documented in Glasgow in 1932 by Christie. ${ }^{25}$

In a carriage study in 1919, Sailer et al. in Georgia, USA, performed nasopharyngeal swabbing on 700 soldiers and detected a pneumococcal carriage rate of $16 \%$. Of the carriers, $5.4 \%$ were Type I and $4.5 \%$ were Type III. They acknowledged that their carriage rates were influenced by recent outbreaks of measles and influenza. ${ }^{57}$ There is also an association with higher pneumococcal carriage rates during times of epidemic upper respiratory tract infection ${ }^{58}$ or pneumococcal pneumonia. ${ }^{59}$

In 1932 Strom documented the decline in serotype I carriage rates after a serotype I outbreak in a Norwegian orphanage the previous year. The serotype I carriage rate fell from $33 \%$ at the height of the outbreak to $16.9 \%$ three months later but was undetectable at all times in neighbouring orphanages unaffected by the outbreak. ${ }^{54}$ The 1937 serotype I pneumococcal pneumonia outbreak at the State Hospital in Worcester, Massachusetts, noted a carriage rate of almost $10 \%{ }^{60}$

Hodges and MacLeod suggest reasons why serotype I and serotype 3 carriage rates varied so much in early carriage studies, particularly with regard to differences in the methodology for specimen processing as they compared several culture methods. ${ }^{61}$ Interestingly, mouse inoculation (favoured by the early Rockefeller Institute studies) yielded higher recovery rates of serotype I and serotype 3 pneumococci than direct plating of throat swabs onto blood agar (similar to the contemporary WHO standard method ${ }^{(2)}$. Hodges and MacLeod also documented carriage of multiple serotypes simultaneously and suggested that the carriage rates of pneumococci rise when the number of cases of pneumococcal pneumonia rise, possibly through the existence of carriers who are contacts of cases. ${ }^{6}$ Additionally, they noted that the longer that men were resident in military barracks, the greater the risk of pneumococcal carriage, suggesting a role for proximity to other people as a factor resulting in increased pneumococcal carriage. ${ }^{61}$ This increased risk of carriage of serotype I during outbreaks has also been documented during outbreaks in the antibiotic era. ${ }^{63,64}$

Different culture methods affecting the observed carriage rates could be a reason why serotype I carriage rates were apparently higher at the start of the twentieth century when mouse inoculation was common but dropped later when carriage study methodology involved plating nasopharyngeal swabs onto blood agar. ${ }^{61}$ Differences in the frequency of sampling and in the populations studied could also account for the differences in carriage rates.$^{65} \mathrm{It}$ is also known that adults in close contact with children have higher carriage rates than adults with no contact with children, although this has not been specifically demonstrated with serotypes I or $3 .{ }^{66}$

It may be reasonable to conclude that serotype I carriage does still occur in communities, that it does increase when numbers of cases of pneumococcal pneumonia due to serotype I increase in the community, but that it is not as readily detected by current standard methods as other serotypes, such as serotype 3 .

\section{PNEUMOCOCCAL NOSOCOMIAL OUTBREAKS}

Possibly the first described pneumococcal nosocomial outbreak was in 1917 when Stillman described two Type I-associated outbreaks. ${ }^{53}$ The first occurred in a 'boys' asylum', where three cases of Type I pneumonia occurred in the same dormitory, and the second at the Rochester State Hospital for the Insane, where there were six cases of pneumonia with two fatalities. Type I pneumococci were recovered from the rooms of the cases and from $2 \%$ of healthy contacts. Stillman also described two episodes of transmission of Type I pneumococci, one between a hospitalised boy with pneumonia and his mother who became symptomatic II days later and another between a woman hospitalised with Type I pneumococcal pneumonia and her five-year-old daughter. This girl probably infected a further child in her foster family (who also developed Type I pneumococcal pneumonia), while she continued to remain healthy herself. ${ }^{53}$

Malloch records a man with Type I lobar pneumonia who infected his daughter who developed pneumococcal peritonitis and then infected her nurse who also developed pneumococcal peritonitis. ${ }^{34}$ A larger community outbreak of Type I pneumonia and otitis media was documented in Massachusetts in 1935.67 
Apart from historical accounts of Type I transmission, there continue to be more recent outbreaks of serotype I pneumococcal disease ${ }^{63,68-73}$ and recently described associations of serotype I causing outbreaks of meningitis in Sub-Saharan Africa. ${ }^{7477}$ Although such outbreaks are uncommon, they often result in fatalities and are potentially preventable in adults using the 23-valent polysaccharide vaccine in susceptible groups such as the elderly, homeless and military personnel living in barracks.

Pneumococcal carriage rates of up to $56 \%$ have been recorded in hospital staff. ${ }^{78}$ The fact that nurses could be healthy carriers of Type I pneumococci and potential disease vectors was documented as early as 1932 in Glasgow where it was noted that Type I carriage could be detected among nurses working in pneumonia wards but not in nurses who had no contact with pneumonia patients in control wards. ${ }^{25}$

It is striking that as recently as 20 years ago, $20 \%$ of hospitalised patients with pneumococcal chest infections had acquired their infection in hospital. ${ }^{79}$ This supports routine pneumococcal vaccination of the elderly who are at increased risk of hospitalisation and may be placed in close proximity to cases..$^{65}$ The spread of infection is often due to the proximity of contact with an index case. ${ }^{65}$ This should therefore be considered a risk factor for healthcare workers in regular close contact with cases of pneumococcal pneumonia and has occupational health considerations for healthcare workers in at-risk groups, such as asplenic staff. It should also influence the proximity of beds and availability of isolation facilities in wards managing patients with pneumonia.

\section{CONTAMINATION AND INFECTION CONTROL}

Possibly the first description of environmental contamination with pneumococci was by Netter in $1897 .{ }^{80}$ Stillman observed that no environmental contamination with pneumococci occurred unless a patient with pneumococcal disease or a healthy carrier had been an occupant of the house tested..$^{53}$ He made detailed accounts of environmental contamination by cases with Type I disease, noting that: 'Of 30 homes where a case of Type I pneumonia had occurred, in 13 instances, or 43 percent, a Type I pneumococcus was recovered from at least I room. In 2 instances a Type I pneumococcus was recovered from 2 rooms. In all, 44 rooms were examined. From 15 of these rooms or 34 percent, a Type I pneumococcus was recovered. ${ }^{53}$

Avery et al. in 1917 also documented environmental contamination by patients with pneumonia. ${ }^{20}$ These observations led them to suggest infection control measures for cases of lobar pneumonia still pertinent today: 'A large percentage of pneumonia patients contaminate the rooms which they occupy, as is shown by the large number of instances in which strictly pathogenic types of pneumococcus can be recovered from the dust of these apartments. This indicates the necessity for thorough cleansing of any room occupied by a case of pneumonia at the close of the period of convalescence. In addition, the daily cleansing of the sick room should be practised in such a way as to avoid dissemination of dust particles. ${ }^{20}$

Although it had been advisable in the pre-antibiotic era, ${ }^{20}$ towards the end of the twentieth century it was deemed impractical to isolate all patients with pneumococcal infection in hospital ${ }^{79}$. Even though the infection was transmissible in the hospital setting, it was felt that the risk posed was generally less than that for other pathogens. Historical public health warnings about the dangers of 'promiscuous spitting', education on 'proper methods of disposing of sputum or expectoration' or advice to 'refrain from kissing'20 seem all too familiar in the aftermath of the recent HINI influenza pandemic.

Isolation still has relevance in the control of an institutional outbreak, " in cases of meningitis or in the case of disease due to multiple antibiotic-resistant pneumococcal clones where it is considered important to "barrier nurse carriers and infected cases in a side room with the door closed. If more than one infected case is detected on the ward, staff and other patients on the ward should be screened for carriage (sputum and nose/throat swab) and eradication of the organism may be attempted. If antibiotics have been given to clear the organisms, three consecutive negative nasopharyngeal cultures are required before eradication may be considered successful. ${ }^{81}$

\section{PNEUMOCOCCAL VACCINATION}

Due to the burden of IPD at the start of the twentieth century and its impact on the war efforts, many attempts were made to formulate monovalent and polyvalent vaccines, some as early as $1911 . .^{82}$ Primarily these vaccines were trialled in the USA and South Africa; they are comprehensively reviewed elsewhere. ${ }^{82,83}$ There was variable success with the prevention of Type I IPD; some vaccines demonstrated no antibody response and no benefit, while groups such as Smillie and colleagues demonstrated substantial benefit. ${ }^{60}$ Often results using Type III polysaccharide were inconclusive..$^{82}$ It was recognised that production of high titres of antisera to Type III were only achieved 'irregularly and with great difficulty' ${ }^{84}$ This was not usually the case with Type I or most other serotypes.

Early vaccines often consisted of inoculation with pneumococcal polysaccharide. It is still recognised that, using the 23-valent pneumococcal polysaccharide vaccine (which remains in routine use), the elderly produce less of an immune response to serotype I or 3 than to many other serotypes. ${ }^{85}$ Serotype 3 polysaccharide was found to be more effective at generating an immune response when conjugated to diphtheria toxoid..$^{86}$ The effect of conjugated serotype 3 polysaccharide vaccination on serotype 3 IPD 
incidence is under surveillance now that Prevenar $13^{8}$ (which contains serotype 3 polysaccharide conjugated to diphtheria toxoid) has entered routine use.

\section{CONCLUSIONS}

There is extensive documentation of the epidemiology of pneumococcal disease in the early twentieth century, much of which is compatible with currently classified serotype I- and serotype 3-related pneumococcal disease. These descriptions are strikingly similar in their accounts of disease manifestations, differences in mortality rates between serotype I and 3 infections,

\section{REFERENCES}

I Scott JA. The preventable burden of pneumococcal disease in the developing world. Vaccine 2007; 25:2398-405. doi:10.1016/j. vaccine.2006.09.008

2 World Health Organization. Pneumococcal conjugate vaccine for childhood immunization - WHO position paper. Wkly Epidemiol Rec 2007; 82:93-104.

3 Kirkham LA, Jefferies JM, Kerr AR et al. Identification of invasive serotype I pneumococcal isolates that express nonhemolytic pneumolysin. J Clin Microbiol 2006; 44:15I-9. doi:10.1128/ ICM.44.I.I5I-I59.2006

4 George RC, Gungabissoon U, Slack MPE et al. Invasive pneumococca disease in England and Wales 1996-2004. In: Proceedings of the Fifth International Symposium on Pneumococci and Pneumococcal Diseases. Alice Springs, Central Australia.April 2-6, 2006. Abstract PO3.I7.

5 Diggle MA, Edwards GSF. The epidemiology of Streptococcus pneumoniae in Scotland between 2003 and 2005. In: Proceedings of the Fifth International Symposium on Pneumococci and Pneumococcal Diseases. Alice Springs, Central Australia. April 2-6, 2006. Abstract: PO3.62.

6 Fletcher M, Leeming J, Cartwright $\mathrm{K}$ et al. Childhood empyema: limited potential impact of 7-valent pneumococcal conjugate vaccine. Pediatr Infect Dis / 2006; 25:559-60. doi:I0. I097/0I.inf.00002 I9535. I420I.Ib

7 Eastham KM, Freeman R, Kearns AM et al. Clinical features, aetiology and outcome of empyema in children in the north east of England. Thorax 2004; 59:522-5. doi:I0.II36/thx.2003.016I05

8 Cole R, MacCallum WG. Pneumonia at a base hospital.JAMA I9I8; 70: I 146-56.

9 Stewart D, Gibson HJ. Acute pneumonia in the recent influenza epidemic. Edinb Med J 1929; 36:607-3I.

I0 Logan WR. A study of the pneumococcus and streptococcus groups in their relation to influenza. Edinb Med J 1921; 26:294-312.

I I Opie EL, Freeman AW, Blake FG et al. Pneumonia following influenza (at Camp Pike, Ark). JAMA 1919; 72:556-65.

12 Glynn EE, Digby L. Bacteriological and clinical observations on pneumonia and empyemata, with special reference to the pneumococcus and to serum treatment. Special report series No. 79. London: Medical Research Council; 1923.

I3 Neufeld F, Händel L. Über Herstellung und Prüfung von Antipneumokokken-Serum und über die Aussichten einer spezifischen Behandlung der Pneumonie. Zeitschr f Immunitätsforsch 1909; 3:159.

14 Dochez AR, Gillespie LJ. A biologic classification of pneumococci by means of immunity reactions. JAMA 1913;61:727-30.

I5 Lister FS. Specific serological reactions with pneumococci from different sources. Pub S Afr Inst Med Res 1913; 2:103-16.

16 Urquhart AL. Serological and morphological characteristics of the pneumococcus. Lancet 1921; 198:1313-7. doi:10.1016/S0I406736(0I)34624-X

17 Schottmüller H. Die Artunterscheidung der für den Menschen pathogenen Streptokokken durch Blutagar. Münch Med Wochenschr 1903; 50:908.

I8 Collins KR. The application of the reaction of agglutination to the pneumococcus. J Exp Med 1905; 7:420-9. doi:I0.1084/jem.7.5.420 prolonged carriage states and environmental reservoirs of pneumococcal infection, along with a marked decline in serotype I pneumococcal disease in the UK and the USA during the 1950s. They can appear different from contemporary accounts of serotype behaviour, perhaps due to the use of antibiotics, which may have altered the natural disease course. However, we neglect these observations of our predecessors to our detriment, particularly in the face of a resurgence of serotype Iand serotype 3-associated disease.

Acknowledgements We thank Professor Tim Mitchell and Dr Andrew Smith, University of Glasgow, for their comments.

19 ParkWH,Williams AW, Oppenheimer A et al. A study of pneumococci: a comparison between the pneumococci found in the throat secretions of healthy persons living in both city and country and those obtained from pneumonic exudates and diseased mucous membranes.J Exp Med 1905; 7:403-19. doi:I0.1084/jem.7.5.403

20 Avery OT, Chickering HT, Cole R et al. Acute lobar pneumonia prevention and serum treatment. New York: Rockefeller Institute Medical Research; 1917.

2I Gransden WR, Eykyn SJ, Phillips I. Pneumococcal bacteraemia: 325 episodes diagnosed at St Thomas's Hospital. BMJ 1985; 290:505-8.

22 Finland M, Sutliff WD. Infections with pneumococcus type III and type VIII. Arch Intern Med 1934; 53:48I-507.

23 Cole R.Antipneumococcus serum. JAMA 1921; 76:1।I-2.

24 Grant MH. Pneumonias in Glasgow and their pneumococcal types. Glasgow Med J 1922; 98:193-5.

25 Christie IM. Type-specific organisms in acute pneumonia and in convalescents and contacts. Lancet 1932;220:1 173-6. doi:10.1016/ SOI40-6736(00)970I3-2

26 Smart LE. The serology of pneumococcal infection: a study of the laboratory diagnosis of pneumococcal infection and the distribution of pneumococcal types. Glasgow: University of Glasgow; 1987.

27 Cowan J, Cruickshank R, Cuthbertson DP et al.Treatment of lobar pneumonia by Felton's serum. Lancet 1930; 216:1387-9. doi:I0.I0I6/S0I40-6736(00)90472-0

28 Grist NR, Landsman JB, Anderson T et al. Studies in the aetiology of pneumonia in Glasgow 1950-5I. Lancet 1952; 259:640-6. doi:I0.I0I6/S0I40-6736(52)90160-8

29 Alston JM, Stewart D. Incidence of the serological types of the pneumococcus in lobar pneumonia. BMJ 1930; 2:860-2.

30 Morgan AD, Buirski G, Calder MA et al. Streptococcus pneumoniae serotypes causing pneumonia in Edinburgh and Nottingham. Lancet 1983; 321:68-9. doi:I0.1016/S0I40-6736(83)9I60I-X

3I Calder MA, McHardy VU, Schonell ME. Importance of pneumococcal typing in pneumonia. Lancet 1970; 295:5-7. doi:I0.1016/S0I406736(70)9052I-0

32 Davidson LS. Proceedings of the Edinburgh Medico-Chirurgical Society. Edinb Med J 1925; 32:67.

33 Armstrong RR. The serological characters of disease producing pneumococci. BMJ 1921; I:259-63.

34 Malloch A. A study of pneumonias and types of pneumococci. QJM 1922; os-15:103-13.

35 Griffith F. The significance of pneumococcal types. J Hyg 1928; 27:8-I59. doi:I0.10I7/S0022172400031879

36 Ferguson FR, Lovell R. An investigation of primary lobar pneumonia in Manchester, 1925-7. QJM 1928; os-22:73-90.

37 Turk DC. Frequencies of pneumococcal types causing serious infections in patients admitted to the Radcliffe Infirmary, Oxford, 1969-77.J Hyg 1978; 81:227-38. doi:I0.I0I7/S0022I72400025055

38 MacFarlane JT, Finch RG, Ward MJ et al. Hospital study of adult community-acquired pneumonia. Lancet 1982; 320:255-8. doi:I0.I0I6/S0I40-6736(82)90334-8 
39 Colman G, Hallas G. Systemic disease caused by pneumococci. J Infect 1983; 7:248-55. doi:10.1016/S0I63-4453(83)97169-4

40 Kyaw MH, Christie P, Clarke SC et al. Invasive pneumococcal disease in Scotland, 1999-200I: use of record linkage to explore associations between patients and disease in relation to future vaccination policy. Clin Infect Dis 2003; 37:1283-91. doi:10.1086/379016

4I Finland MF, Barnes MW. Changes in occurrence of capsular serotypes of Streptococcus pneumoniae at Boston City Hospital during selected years between 1935 and 1974.J Clin Microbiol 1977; 5:I54-66.

42 Smeall JT. Types of pneumococci in relation to disease. BMJ 1931; I:66I-3. doi: I0.I I36/bmj.I.3667.66I

43 Whittle $\mathrm{CH}$. Further observations on pneumococcal infections. BMJ 1929; 2:898-900. doi: I0.1 136/bmj.2.3593.898

44 Thomas WS. Type I pneumonia and its serum treatment. JAMA 1921:77:2101-3.

45 McLelland JE. Importance of blood cultures in pneumonia. JAMA |918; 71:|299-301.

46 Lyon AB. Bacteriologic studies of the one hundred and sixty five cases of pneumonia and postpneumonic empyema in infants and children. Am J Dis Child 1922; 23:72-87.

47 Martens P, Worm SW, Lundgren B et al. Serotype-specific mortality from invasive Streptococcus pneumoniae disease revisited. BMC Infectious Diseases 2004; 4:21. doi:I0.1 I86/I47|-2334-4-2I

48 Berg S, Trollfors B, Persson E et al. Serotypes of Streptococcus pneumoniae isolated from blood and cerebrospinal fluid related to vaccine serotypes and to clinical characteristics. Scand J Infect Dis 2006; 38:427-32. doi:10.1080/00365540500532852

49 Rückinger S, von Kries R, Reinert RR et al. Childhood invasive pneumococcal disease in Germany between 1997 and 2003: variability in incidence and serotype distribution in absence of general pneumococcal conjugate vaccination. Vaccine 2008; 26:3984-6. doi:10.1016/j.vaccine.2008.04.031

50 Sjöström K, Spindler C, Ortqvist A et al. Clonal and capsular types decide whether pneumococci will act as a primary or opportunistic pathogen. Clin Infect Dis 2006; 42:45I-9. doi:10.1086/499242

5 I Stillman EG. A contribution to the epidemiology of lobar pneumonia.J Exp Med 1916; 24:65 I-70. doi: I0.1084/jem.24.6.65 I

52 Dochez AR, Avery OT. The occurrence of carriers of diseaseproducing types of pneumococcus. J Exp Med 1915; 22:105-13. doi:10.1084/jem.22.1.105

53 Stillman EG. Further studies on the epidemiology of lobar pneumonia.J Exp Med 1917; 26:513-35. doi:10.1084/jem.26.4.513

54 Strom A. An epidemic of croupous pneumonia caused by pneumococcus type I.J Infect Dis 1932; 50:430-6.

55 Brueggemann AB, Griffiths DT, Meats E et al. Clonal relationships between invasive and carriage Streptococcus pneumoniae and serotype- and clone-specific differences in invasive disease potential.J Infect Dis 2003; 187:I 424-32. doi:10.1086/374624

56 Meyer J. Types of pneumococci in the throats of one hundred normal persons. JAMA 1920; 75:1268-9.

57 Sailer J, Hall MW, Wilson RL et al. A study of pneumococcus carriers. Arch Intern Med 1919; 24:600-10.

58 Gordon JE. The relationship of the pneumococcus to acute infections of the upper respiratory tract in man.J Infect Dis 1921; 29:437-61.

59 Stebbins EL, Perkins JE, Rogers ES et al. Prevalence of pneumococcus carriers: specific types in epidemic and non-epidemic areas. $\mathrm{Am} J$ Public Health 1940; 30:349-60. doi:10.2105/AJPH.30.4.349

60 Smillie WG, Warnock GH, White HJ. A study of a type I pneumococcus epidemic at the State Hospital at Worcester, Mass. Am J Public Health 1938; 28:293-302. doi: 10.2105/AJPH.28.3.293

61 Hodges RG, MacLeod CM, Bernhard WG. Epidemic pneumococcal pneumonia III. Pneumococcal carrier studies. Am J Hyg 1946; 44:207-30.

62 O'Brien KL, Nohynek H. Report from a WHO Working Group: standard method for detecting upper respiratory carriage of Streptococcus pneumoniae. Pediatr Infect Dis J 2003; 22:el-II. doi:I0.1097/0I.inf.0000049347.42983.77

63 DeMaria A, Browne K, Berk SL et al. An outbreak of type I pneumococcal pneumonia in a men's shelter.JAMA 1980; 244:1446-9.
64 Dagan R, Gradstein S, Belmaker B et al. An outbreak of Streptococcus pneumoniae serotype $I$ in a closed community in Southern Israel. Clin Infect Dis 2000; 30:319-2I. doi:10.1086/313645

65 Davies AJ, Lockley MR. A prospective survey of hospital crossinfection with Streptococcus pneumoniae. J Hosp Infect 1987; 9:162-8. doi:I0.1016/0I95-670I(87)90055-7

66 Hendley JO, Sande MA, Stewart PM et al. Spread of Streptococcus pneumoniae in families. I. Carriage rates and distribution of types. J Infect Dis 1975; |32:55-6|.

67 Gilman BB, Anderson GW. A community outbreak of type I pneumococcus infection. Am J Hyg 1938; 28:345-58.

68 Mercat A, Nguyen J, Dautzenberg B. An outbreak of pneumococcal pneumonia in two men's shelters. Chest 1991;99:147-51.doi:10.1378/ chest.99.I.147

69 Musher DM, Groover JE, Reichler MR et al. Emergence of antibody to capsular polysaccharides of Streptococcus pneumoniae during outbreaks of pneumonia: association with nasopharyngeal colonization. Clin Infect Dis 1997; 24:44I-6.

70 Thakker B, Gorman LJ, McNamee S et al. An outbreak of Streptococcus pneumoniae serotype $I$ in a geriatric ward. In: Program and abstracts of the 38th Interscience Conference on Antimicrobial Agents and Chemotherapy. Washington, DC:American Society for Microbiology; 1998. K-34.

7I Sirotnak AP, Eppes SC, Klein JD. Tubo-ovarian abscess and peritonitis caused by Streptococcus pneumoniae serotype 1 in young girls. Clin Infect Dis 1996; 22:993-6.

72 Proulx JF, Dery S, Jette LP et al. Pneumonia epidemic caused by a virulent strain of Streptococcus pneumoniae serotype I in Nunavik, Quebec. Can Commun Dis Rep 2002; 28:129-31.

73 Gupta A, Khaw F-M, Stokle EL et al. Outbreak of Streptococcus pneumoniae serotype I pneumonia in a United Kingdom school. BMJ 2008; 337:a2964. doi:10.1 I36/bmj.a2964

74 Greenwood B. Pneumococcal meningitis epidemics in Africa. Clin Infect Dis 2006; 43:70I-3. doi: I0.1086/506943

75 Butler JC, Levine OS. The changing landscape of epidemic bacterial meningitis in Africa: new opportunities for prevention.J Infect Dis 2005; 192:189-91. doi:10.1086/431154

76 Scott JA, Hall AJ, Hannington A et al. Serotype distribution and prevalence of resistance to benzylpenicillin in three representative populations of Streptococcus pneumoniae isolates from the coast of Kenya. Clin Infect Dis 1998; 27:1442-50. doi:10.1086/5I50I3

77 Yaro SY, Lourd M, Traore $Y$ et al. Epidemiological and molecular characteristics of a highly lethal pneumococcal meningitis epidemic in Burkina Faso. Clin Infect Dis 2006;43:693-700. doi: 10.1086/506940

78 Finland M. Excursions into epidemiology: selected studies during the past four decades at Boston City Hospital. J Infect Dis 1973; 128:76-124.

79 Davies AJ, Dyas A. Hospital-acquired infection with Streptococcus pneumoniae. J Hosp Infect 1985;6:98-101. doi:10.1016/S0195670I(85)80025-6

80 Netter LD. Présence du pneumocoque dans les poussieres d'une salle d'hôpital. C R Soc Biol Paris 1897; 4:538-40.

8I Ridgway EJ, Allen KD, Galloway $A$ et al. Penicillin resistant pneumococci in a Merseyside hospital.J Hosp Infect 1991; 17:1523. doi: I0.1016/0I95-670I(91)90073-H

82 Siegel M, Muckenfuss RS, Schaeffer M et al. A study in active immunization against epidemic influenza and pneumococcus pneumonia at Letchworth Village. Am J Epidemiol 1942; 35:55-96.

83 MacLeod CM, Hodges RG, Heidelberger $M$ et al. Prevention of pneumococcal pneumonia by immunization with specific capsular polysaccharides. J Exp Med 1945; 82:445-65. doi:10.1084/jem.82.6.445

84 MacLeod CM. Treatment of pneumonia with antipneumococcal rabbit serum. Bull NYAcad Med 1939; 15:1 16-24.

85 Rubins JB, Alter M, Loch J et al. Determination of antibody responses of elderly adults to all 23 capsular polysaccharides after pneumococcal vaccination. Infect Immun 1999; 67:5979-84.

86 Nurkka A, Åhman H,Yaich M et al. Serum and salivary anti-capsular antibodies in infants and children vaccinated with octavalent pneumococcal conjugate vaccines, PncD and PncT. Vaccine 2002; 20:194-20I. doi:I0.10I6/S0264-4I0X(0I)00250-X 